\title{
Symmetrical and Unsymmetrical Schiff Bases Derived from 3,4-Diaminobenzophenone: Synthesis and Thermodynamics of Five Coordinated Tertiaryphosphine Cobalt(III) Complexes
}

\author{
Khosro Mohammadi,1,* Mozaffar Asadi, ${ }^{2}$ Moslem Setoodeh Khah, ${ }^{3}$ Hajar Sepehrpour ${ }^{2}$
}

\author{
${ }^{1}$ Chemistry Department, Faculty of Sciences, Persian Gulf University, Bushehr 75169, I.R. Iran \\ 2 Chemistry Department, College of Sciences, Shiraz University, Shiraz 71454, I.R. Iran \\ 3 Department of Inorganic Chemistry, Faculty of Chemistry, University of Kashan, Kashan, 87317-51167 I.R Iran \\ * Corresponding author's e-mail address: khmohammadi@pgu.ac.ir
}

RECEIVED: July 2, 2015 * REVISED: February 10, 2016 * ACCEPTED: July 19, 2016

\begin{abstract}
Some new cobalt(III) complexes described as $\left[\mathrm{Co}(\mathrm{Chel})\left(\mathrm{PBu}_{3}\right)\right] \mathrm{ClO}_{4} \times \mathrm{H}_{2} \mathrm{O}$ where (Chel) is the deprotonated form of a series of symmetric and unsymmetrical Schiff base ligands containing 3,4-diaminobenzophenone (3,4-DABP) and substituted salicylaldehyde moieties and $\left[\mathrm{Co}(\mathrm{Chel})\left(\mathrm{PMePh}_{2}\right)\right] \mathrm{ClO}_{4} \times \mathrm{H}_{2} \mathrm{O}$ where (Chel) is [ $\left.\mathrm{N}^{\prime}-(5-\mathrm{BrSalDABP})\right]$ were synthesized and characterized by ${ }^{1} \mathrm{H} \mathrm{NMR,} \mathrm{IR,} \mathrm{UV-Vis} \mathrm{spectroscopy,}$ and elemental analysis. The formation constants and the thermodynamic parameters were determined spectrophotometrically for 1:1 adduct formation of the new complexes as acceptor with some aliphatic amines such as benzylamine, $n$-butylamine, sec-butylamine and tertbutylamine as donors in $\mathrm{DMSO}$ solvent in constant ionic strength $\left(I=0.1 \mathrm{M} \mathrm{NaClO}_{4}\right)$. The formation constants change according to the following trend due to the steric and the electronic factors of the cobalt(III) complexes: $\mathrm{N}^{\prime}-5-\mathrm{OMe}>\mathrm{N}^{\prime}-5-\mathrm{H}>\mathrm{N}^{\prime}-5-\mathrm{Br}>\mathrm{N}^{\prime}-5-\mathrm{Cl} ; \mathrm{N}, \mathrm{N}^{\prime}-3-\mathrm{OMe}>\mathrm{N}, \mathrm{N}^{\prime}-4-\mathrm{Ome}$.

The trend of the formation constants of cobalt(III) Schiff base complexes toward a given donor according to the axial ligand is as follow: $\mathrm{PBu}_{3}>\mathrm{PMePh}_{2}$. Also, the following binding trend of the donors toward a given cobalt(III) Schiff base complex is obtained: benzylamine > $n$-butylamine $>$ sec-butylamine $>$ tert-butylamine.
\end{abstract}

Keywords: cobalt(III) complex, unsymmetrical Schiff base, thermodynamic, formation constants.

\section{INTRODUCTION}

$\mathrm{C}$ obalt(III) and cobalt(II) Schiff base complexes derived from symmetrical and unsymmetrical Schiff bases have gained importance for their applicability in the biological field ${ }^{[1-4]}$ and catalytic activity. ${ }^{[5-7]}$

The discovery of certain cobalt(III) Schiff base complexes that have antiviral properties prompted scientists to initiate an investigation of $\mathrm{Co}$ (III) interactions with proteins and nucleic acids. ${ }^{[8,9]}$ Since complexes with relatively labile axial ligands exhibit higher activity, it is suspected that the axial binding of $\mathrm{Co}$ (III) to biological targets is somehow involved in the mechanism of action. ${ }^{[10,11]}$ In this regard, the Schiff base complexes have acquired special significance due to their interesting magnetic properties. ${ }^{[12]}$ Apart from these examples, cobalt complexes of tetradentate Schiff base ligands have been widely used to mimic cobalamine $\left(B_{12}\right)$ coenzymes. ${ }^{[13-15]}$ Cobalt(III) Schiff base complexes with amines axial ligands have been shown to inhibit the replication of the ocular hepes virus.[16] Many experimental and theoretical investigations have been done on cobalt Schiff base complexes because of their interesting drug properties such as antiviral drugs. ${ }^{[17]}$

In continuation of our works on the unsymmetrical Schiff base complexes, ${ }^{[18-21]}$ we synthesized and characterized some new unsymmetrical cobalt(III) Schiff base complexes. The formation constants and the thermodynamic parameters were determined spectrophotometrically for $1: 1$ adduct formation of the new complexes as acceptor with some aliphatic amines such as benzylamine, $n$-butylamine, sec-butylamine and tert-butylamine as donors in DMSO solvent with the goal of evaluating the effect of axial ligands and the substituted equatorial Schiff base ligands. 


\section{EXPERIMENTAL}

\section{Materials}

The materials, salicylaldehyde, 3-methoxysalicylaldehyde, 4-methoxysalicylaldehyde 5-methoxysalicylaldehyde, 5bromosalicylaldehyde, 5-chlorosalicylaldehyde, 3,4-diaminobenzophenone, cobalt(II) acetate tetrahydrate, tri- $n$ butylphosphine, diphenylmehylphosphine, methanol, dimethylsulfoxide, benzylamine, $n$-butylamine, sec-butylamine, tert-butylamine, diethylamine, di( $n$-butyl)amine, tri( $n$-butyl)amine and sodium perchlorate monohydrate were purchased from Merck and Fluka. Anal. Grade solvents from Merck were used without further purification. The diamine and salicylaldehyde were distilled before use.

\section{Analytical Instruments}

The infrared spectra of all the ligands and their complexes were recorded in the range $4000-400 \mathrm{~cm}^{-1}$ using a Shimadzu FTIR-8300 spectrophotometer applying the $\mathrm{KBr}$ disc technique. The UV-Visible absorption spectra were recorded using Perkin-Elmer Lambda 2 spectrophotometer. The elemental analysis was carried out by Thermo FinniganFlash-1200. The ${ }^{1} \mathrm{H}$ NMR spectra were recorded by a Bruker Avance DPX $250 \mathrm{MHz}$ spectrometer.

\section{Synthesis of the Ligands and Their Cobalt Complexes}

Symmetrical and unsymmetrical Schiff base ligands were prepared in a similar manner according to the literatures. ${ }^{[22,23]}$ The cobalt(III) Schiff base complexes shown in Scheme 1 , were prepared by the methods described in the literature. ${ }^{[2]}$ To a refluxing solution of the tetradentate ligands (1 mmol), in $25 \mathrm{~mL}$ mixed solvent methanol / chloroform (15 / 10) under $\mathrm{N}_{2}$ atmosphere, was added a solution of $\mathrm{Co}(\mathrm{OAc})_{2} \times 4 \mathrm{H}_{2} \mathrm{O}(0.25 \mathrm{~g}, 1 \mathrm{mmol})$ in methanol
(5 $\mathrm{mL}$ ). The brown solution is formed immediately. After $30 \mathrm{~min}$, appropriate phosphine $(0.8 \mathrm{mmol})$ was added to the solution. The reaction mixture was refluxed for an hour. The cobalt(II) formed complex was oxidized by blowing air into the solution for $2 \mathrm{~h}$, and the solution was filtered. An appropriate amount of sodium perchlorate was added to the filtrate. The resulting deep brown crystals were formed after $48 \mathrm{~h}$. The crystals were washed with some methanol and purified by re-crystallization in methanol and finally, the complexes dried in vacuum at $T=323 \mathrm{~K}$ for $48 \mathrm{~h}$. (Scheme 1).

Caution: Although no difficulties were experiences, cobalt(III) complexes were isolated as their perchlorates, and therefore, they should be handled as potentially explosive compounds.

\section{Thermodynamic Studies}

The formation constants have been determined by UV-Vis absorption spectroscopy from the reaction of the acceptors with the donors in DMSO solvent, according to the following equations:

$$
\left[\mathrm{Co}(\text { Chel })\left(\mathrm{PR}_{3}\right)\right]^{+}+\mathrm{Y} \rightleftharpoons\left[\mathrm{Co}(\text { Chel })\left(\mathrm{PR}_{3}\right) \mathrm{Y}\right]^{+}
$$

where Chel $=\mathrm{N}, \mathrm{N}^{\prime}-3-\mathrm{OMeSalDABP}, \mathrm{N}, \mathrm{N}^{\prime}-4-\mathrm{OMeSalDABP}$, $\mathrm{N}, \mathrm{N}^{\prime}-5-\mathrm{HSalDABP}, \mathrm{N}, \mathrm{N}^{\prime}-5-\mathrm{OMeSalDABP}, \quad \mathrm{N}^{\prime}-5$-BrSalDABP, $N^{\prime}-5-C l S a l D A B P$;

$$
\mathrm{Y}=\text { benzylamine; } \mathrm{PR}_{3}=\mathrm{PBu}_{3}
$$

and where Chel $=\mathrm{N}^{\prime}-5-\mathrm{BrSalDABP}$;

$\mathrm{Y}=n$-butyl-, sec-butyl-, ter-butyl-, benzylamine;

$\mathrm{PR}_{3}=\mathrm{PBu}_{3}$

and where Chel $=N^{\prime}-5-B r S a l D A B P$;

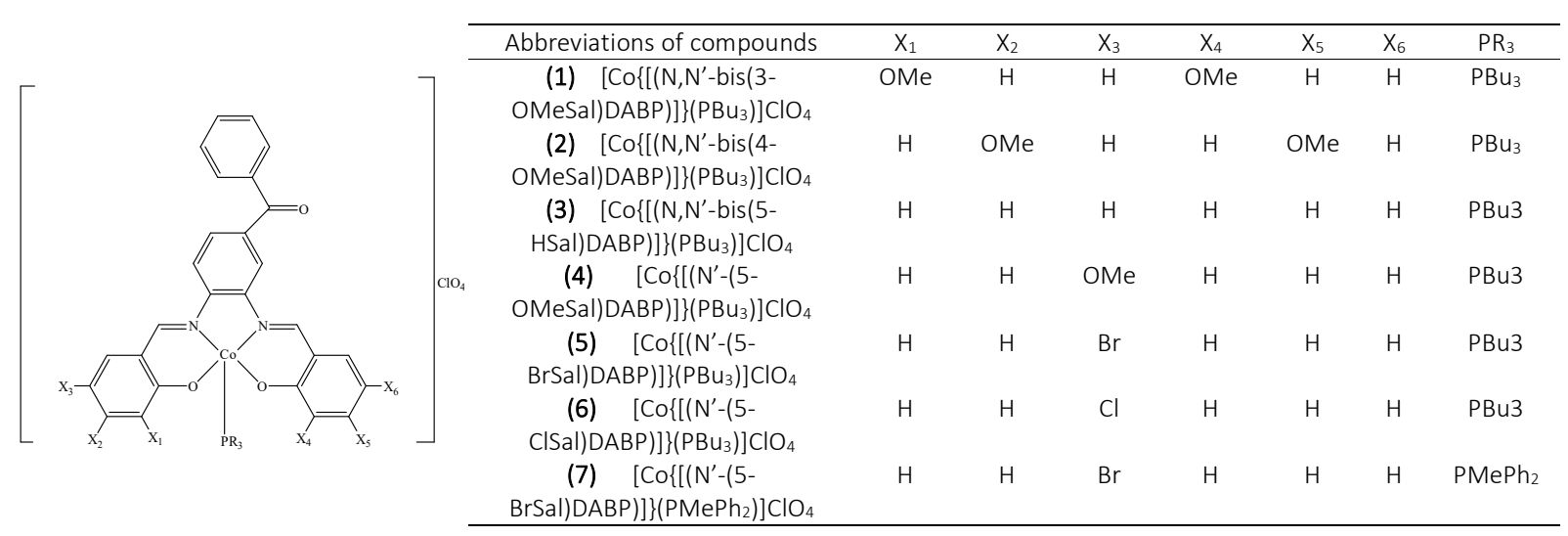

Scheme 1. The structure of the Schiff base complexes. 


$$
\mathrm{Y}=\text { benzylamine; } \mathrm{PR}_{3}=\mathrm{PMePh}_{2}
$$

A solution from each complex with concentration at about $5 \times 10^{-5} \mathrm{~mol} \mathrm{~L}^{-1}$ and constant ionic strength $(I=$ $0.1 \mathrm{~mol} \mathrm{~L}^{-1}$ ) by sodium perchlorate was prepared. In a typical titration, $2.5 \mathrm{~mL}$ of this solution was transferred into the thermostated cell compartment of the UV-Visible instrument, which kept at constant temperature $( \pm 0.1 \mathrm{~K})$ by circulating water and titrated by the given amine. The titration was done by adding aliquots of the amine with a Hamilton microlitre syringe. The donor's concentration was varied in 1-10 folds in excess.

The absorption measurements were carried out at various wavelengths where the difference in absorption was the maximum after the equilibrium assessed. The formed adduct showed an absorption different from the acceptor, while the donors showed no absorption at those wavelengths. As an example, the variation of the electronic spectra for (2), titrated with benzylamine at $T=293 \mathrm{~K}$ in DMSO is shown in Figure 1. The isosbestic points for this system show that there is only one reaction in equilibrium. The same procedure was repeated for other systems.

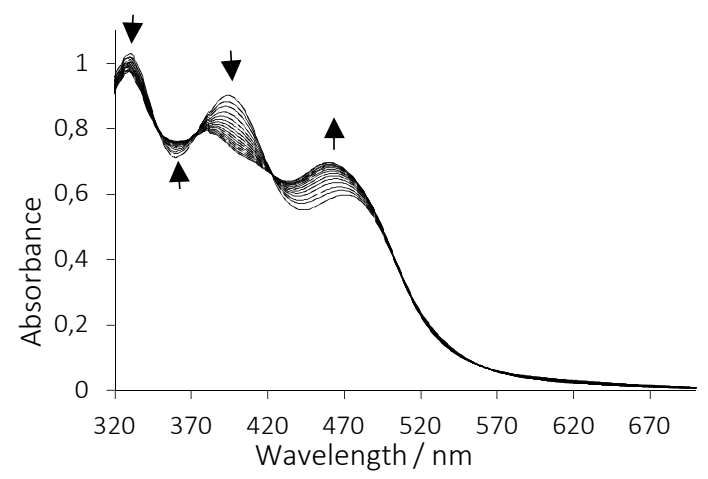

Figure 1. The variation of the electronic spectra of (2) titrated with benzylamine at $T=293 \mathrm{~K}$ in DMSO.

\section{RESULTS AND DISCUSSION}

The complexes were obtained by mixing the Schiff bases with cobalt ion and phosphines in a 1:1:1 ratio. The air stable compounds are not soluble in water but soluble in some organic solvents. The compounds were characterized by various physico-chemical techniques, viz. ${ }^{1} \mathrm{H} N M R, I R, U V-V i s$ spectroscopy and elemental analysis. The elemental analysis and some physical data for the complexes are listed in Table 1.

\section{${ }^{1} \mathbf{H}$ NMR Spectra}

The ${ }^{1} \mathrm{H}$ NMR of the complexes are consistent with the suggest fourmulation and show that the cobalt in these complexes are low spin. The $\mathrm{O}-\mathrm{H}$ protons of the phenolic groups for the tetradentate ligands have signals in the range 12.4-13.4 ppm. The absence of these proton's signals in the complexes show that the Schiff bases are coordinated. The azomethine protons appear at $9.1 \mathrm{ppm}$. By comparing the ${ }^{1} \mathrm{H}$ NMR spectra of the Schiff base ligands and their cobalt(III) complexes, it is noted that there is a down field shift ( $\approx 0.2 \mathrm{ppm}$ ) in the frequency of azomethine protons in the complexes confirming coordination of the metal ion to these groups. The complexes show the aromatic protons as multiplet in the range $6.5-7.8 \mathrm{ppm}$. The proton's chemical shifts for the coordinated $\mathrm{PBu}_{3}$ in the Schiff base complexes appear at $\delta=0.7$ up to $1.7 \mathrm{ppm}$. The proton's chemical shifts for the $-\mathrm{CH}_{3}$ group in $\mathrm{PMePh}_{2}$ appear at $\delta=1.2-1.4 \mathrm{ppm}$. These results are in agreement with the previous results observed for metal complexes of phosphines as axial ligand[18,21] (Table 2).

By comparing the ${ }^{1} \mathrm{H}$ NMR spectra of symmetrical and unsymmetrical Schiff base ligands and their complexes, it is noted that there is slight difference between hydroxy $(\mathrm{O}-\mathrm{H})$ and imine $(\mathrm{H}-\mathrm{CN})$ signals in unsymmetrical compounds. ${ }^{[20,22,23,25,26]}$ For our unsymmetrical Schiff bases, the $\mathrm{O}-\mathrm{H}$ protons of the phenolic groups appear at different chemical shifts. The azomethine protons of the Schiff bases and their complexes almost appear at same place.

Table 1. The analytical and some physical data of the cobalt(III) complexes.

\begin{tabular}{|c|c|c|c|c|c|c|}
\hline \multirow{2}{*}{ Compounds } & \multirow{2}{*}{ Color } & \multirow{2}{*}{ Yields / \% } & \multirow{2}{*}{ m.p. $/{ }^{\circ} \mathrm{C}$} & \multicolumn{3}{|c|}{ Anal. Found (Calcd) / \% } \\
\hline & & & & C & $\mathrm{H}$ & $\mathrm{N}$ \\
\hline (1) & Red brown & 65 & $>250$ & $57.56(57.45)$ & $5.95(6.00)$ & $3.53(3.27)$ \\
\hline$(2)$ & Red brown & 70 & $>250$ & $57.50(57.45)$ & $5.92(6.00)$ & $3.28(3.27)$ \\
\hline (3) & Red brown & 63 & $>250$ & $55.88(58.76)$ & $5.67(5.94)$ & $3.74(3.51)$ \\
\hline (4) & Red brown & 45 & $>250$ & $57.58(57.45)$ & $5.61(6.00)$ & $3.66(3.21)$ \\
\hline (5) & Red brown & 68 & $>250$ & $53.65(53.47)$ & $5.21(5.29)$ & $3.48(3.20)$ \\
\hline (6) & Red brown & 42 & $>250$ & $56.48(56.33)$ & $5.18(5.58)$ & $3.54(3.37)$ \\
\hline (7) & Red brown & 38 & $>250$ & $55.25(54.97)$ & 3.57 (3.69) & $3.59(3.21)$ \\
\hline
\end{tabular}


Table 2. ${ }^{1} \mathrm{H}$ NMR spectral data of the cobalt(III) complexes in $\mathrm{DMSO}^{-\mathrm{d}_{6}}(\delta, \mathrm{ppm})$.

\begin{tabular}{ccccc}
\hline Compounds & $\mathrm{H}-\mathrm{C}=\mathrm{N}$ & $\mathrm{Ar}-\mathrm{H}$ & $-\mathrm{OCH}_{3}$ & $-\mathrm{CH}_{3},-\mathrm{CH}_{2}$ \\
\hline$(1)$ & 8.9 & $6.7-8.6$ & 3.9 & $0.7-1.7$ \\
$(2)$ & 8.9 & $6.3-8.6$ & 3.8 & $0.7-1.6$ \\
$(3)$ & 9.1 & $6.6-8.6$ & - & $0.7-1.6$ \\
$(4)$ & 9.1 & $6.6-8.8$ & 3.8 & $0.7-1.6$ \\
$(5)$ & 9.1 & $6.8-8.7$ & - & $0.7-1.5$ \\
$(6)$ & 9.1 & $6.7-8.9$ & - & $0.7-1.3$ \\
$(7)$ & 8.8 & $6.6-8.8$ & - & $1.2-1.4\left(-\mathrm{CH}_{3}\right)$ \\
\hline
\end{tabular}

\section{Infrared Spectral Studies}

The IR spectra of the complexes exhibit absorption band around $3400 \mathrm{~cm}^{-1}$ that is attributed to $\mathrm{O}-\mathrm{H}$ stretching due to the water presence. ${ }^{[27]}$ The bands appearing at $1604-$ $1610 \mathrm{~cm}^{-1}$ are due to azomethine group. ${ }^{[28]}$ IR absorption bands in the $1645-1655 \mathrm{~cm}^{-1}$ region in the complexes can be attributed to the $\mathrm{C}=\mathrm{O}$ stretching vibrations. The strong absorption bands in the $2800-3100 \mathrm{~cm}^{-1}$ region are related to $(\mathrm{C}-\mathrm{H})$ vibrations. In cobalt(III) complexes containing $\mathrm{PBu}_{3}$, the bands are very stronger, assignable to $\mathrm{C}-\mathrm{H}$ vibrations of $\mathrm{PBu}_{3}$. The strong bands around $1400-1600 \mathrm{~cm}^{-1}$ are due to the skeleton stretching vibrations of the benzene rings. ${ }^{[29]}$ Assignment of the proposed coordination sites is further supported by the appearance of bands at 500$580 \mathrm{~cm}^{-1}$ and $400-500 \mathrm{~cm}^{-1}$ which could be attributed to $v_{\mathrm{N}-\mathrm{M}}$ and $v_{\mathrm{O}-\mathrm{M}}$, respectively. ${ }^{[30,31]}$ The intense band in 1080$1100 \mathrm{~cm}^{-1}$ is assigned to non-coordinating perchlorate ion. ${ }^{[32]}$ IR spectral data of the compounds and their relative assignments are shown in Table 3.

By comparing the FTIR spectra of symmetrical and unsymmetrical Schiff base ligands and their complexes, it is noted that there is not noticeable difference between FTIR spectra of the symmetrical and unsymmetrical compounds. $[20,22,23,25,26]$

\section{The Electronic Spectra}

All the cobalt(III) complexes show two bands in the range of 370-500 $\mathrm{nm}$, which are attributed to $d \rightarrow \pi^{*}$ transition. The band at lower energy is attributable to $d \rightarrow \pi^{*}$ transition associated with azomethine chromophore and the band at higher energy arised from $d \rightarrow \pi^{*}$ transition within the phenyl rings. ${ }^{[33]}$. The band in the range of 320$340 \mathrm{~nm}$ is attributed to $\pi \rightarrow \pi^{*}$ intraligand transition of the conjugated system ${ }^{[34]}$ (Table 4); this band did not really change in all the adduct reaction studies. The $d-d$ bands even at high concentration of the complexes were obscured by an intense band of the charge transfer.

\section{The Formation Constants and the Thermodynamic Parameters}

The formation constants of the various cobalt(III) Schiffbase complexes were calculated by using, Ketelaar's [Eq. (2)].[35]

$$
\frac{c_{A}^{0} C_{D}^{0}}{A-A_{A}^{0}-A_{D}^{0}}=\frac{1}{\varepsilon_{C}-\varepsilon_{A}-\varepsilon_{D}}\left[\frac{1}{K}+\left(c_{A}^{0}+c_{D}^{0}\right)\right]
$$

Table 4. The UV-Vis data of the compounds in DMSO solvent.

\begin{tabular}{cc}
\hline Compounds & $\lambda_{\max } / \mathrm{nm}$ \\
\hline$(1)$ & $472,393,327$ \\
$(2)$ & $471,391,329$ \\
$(3)$ & $485,389,319$ \\
$(4)$ & $468,388,329$ \\
$(5)$ & 497,383 \\
$(6)$ & 500,385 \\
(7) & $498,385,311(\mathrm{sh})^{(\mathrm{a})}$ \\
\hline
\end{tabular}

(a) $\mathrm{sh}=$ shoulder.

Table 3. IR spectral data of the cobalt(III) complexes $\left(\mathrm{cm}^{-1}\right)$.

\begin{tabular}{ccccccccc}
\hline Compounds & $v_{\mathrm{O}-\mathrm{H}}$ & $v_{\mathrm{C}-\mathrm{H}}$ & $v_{\mathrm{C}=\mathrm{O}}$ & $v_{\mathrm{C}=\mathrm{N}}$ & $v_{\mathrm{C}=\mathrm{C}}$ & $v_{\mathrm{N}-\mathrm{M}}$ & $v_{\mathrm{O}-\mathrm{M}}$ & $v_{\mathrm{Cl} 104}$ \\
\hline$(1)$ & 3386 & 2950,2931 & 1658 & 1604,1577 & 1539,1461 & 540 & 424 & 1091 \\
$(2)$ & 3433 & 2939,2927 & 1654 & 1608,1569 & 1500,1554 & 532 & 462 & 1095 \\
$(3)$ & 3431 & 2956,2929 & 1651 & 1611,1577 & 1523,1435 & 556 & 461 & 1090 \\
$(4)$ & 3391 & 2929,2962 & 1651 & 1609,1578 & 1526,1435 & 568 & 458 & 1092 \\
$(5)$ & 3383 & 2930,2957 & 1645 & 1609,1578 & 1514,1445 & 623 & 441 & 1090 \\
$(6)$ & 3445 & 2963,2930 & 1651 & 1611,1578 & 1572,1435 & 623 & 455 & 1090 \\
$(7)$ & 3418 & 3049,2929 & 1645 & 1605,1576 & 1512,1435 & 625 & 462 & 1090 \\
\hline
\end{tabular}


where $c_{A}^{0}$ and $c_{D}^{0}$ are the initial concentrations $\left(\mathrm{mol} \mathrm{L}^{-1}\right)$ of the acceptor and the donor, respectively; The linear plots of $P$ against $C$, where $P$ is defined as $P=\left(C_{A}^{0} C_{D}^{0}\right) /$ $\left(A-A_{A}^{0}-A_{D}^{0}\right)$ and $C=\left(C_{A}^{0}+C_{D}^{0}\right)$ for (2) titrated with benzylamine at various temperatures in DMSO are shown in Figure 2. These plots signify that only a $1: 1$ complex is formed. The linear plots of $P$ against $C$ should produce a straight line if only a 1:1 complex, and would lead to a curve if $1: 2$ and or a mixture of $1: 1$ and $1: 2$ complexes are present in the system. The formation constants were calculated from the ratio of slope to the intercept by least square method (Table 5). Similar plots were obtained for other systems.

The thermodynamic parameters of the complexes were determined by using of the well-known van't Hoff [Eq. (3)]:

$$
\ln K_{\mathrm{f}}=\frac{-\Delta H^{\circ}}{R T}+\frac{\Delta S^{\circ}}{R}
$$

where $K_{\mathrm{f}}$ is the formation constant, $R$ is the gas constant and $T$ is the temperature in Kelvin. The thermodynamic parameters of the complexes were obtained from the linear plots of $\ln K_{\mathrm{f}}$ against $1 / T$. The values of $\Delta H^{\circ}$ and $\Delta S^{\circ}$ were obtained from the slope and the intercept, respectively by using Excel computer program. The $\Delta G^{\circ}$ of complex formation was obtained according to [Eq. (4)]:

$$
\Delta \mathrm{G}^{\circ}=-R T \ln K_{\mathrm{f}}
$$

The linear plot for (2) titrated with benzylamine at various temperatures in DMSO is shown in Figure 3. The similar plots are obtained for other systems.

\section{The Effects of the Equatorial Schiff base Ligands}

\section{THE ELECTRONIC EFFECT OF THE SUBSTITUENTS ON THE SCHIFF BASE LIGANDS}

The equatorial ligands play important role in the stability and the reactivity of their complexes. Herein, the electronic effect of substituted groups bonded to the Schiff base ligands coordinated to cobalt(III) was studied.

The trend of the formation constants for the complexes, $\left[\mathrm{Co}(\mathrm{Chel})\left(\mathrm{PBu}_{3}\right)\right]^{+}$, with benzylamine in DMSO solvent where Chel is unsymmetrical and symmetrical equatorial Schiff base with the different substituted groups, is as following:

$$
\mathrm{N}^{\prime}-5-\mathrm{OMe}>\mathrm{N}, \mathrm{N}^{\prime}-5-\mathrm{H}>\mathrm{N}^{\prime}-5-\mathrm{Br}>\mathrm{N}^{\prime}-5-\mathrm{Cl} \text {. }
$$

It is observed that the formation constants decrease according to the sequence $\mathrm{OMe}>\mathrm{H}>\mathrm{Br}>\mathrm{Cl}$. It seems that
Table 5. The formation constants, $10^{-2} K_{\mathrm{f}}\left(\mathrm{L} \mathrm{mol}^{-1}\right)$, for the interaction between the cobalt(III) complexes with benzylamine in DMSO at various temperatures (K).

\begin{tabular}{ccccc}
\hline Compounds & 293 & 303 & 313 & 323 \\
\hline$(1)$ & $31.7 \pm 0.6$ & $27.1 \pm 0.5$ & $18.8 \pm 0.6$ & $17.9 \pm 0.7$ \\
$(2)$ & $17.4 \pm 0.2$ & $15.4 \pm 0.8$ & $14.5 \pm 0.6$ & $12.8 \pm 0.7$ \\
$(3)$ & $7.5 \pm 0.4$ & $6.1 \pm 0.1$ & $5.1 \pm 0.3$ & $4.3 \pm 0.3$ \\
$(4)$ & $12.5 \pm 0.5$ & $9.8 \pm 0.6$ & $8.1 \pm 0.1$ & $6.9 \pm 0.2$ \\
$(5)$ & $6.4 \pm 0.3$ & $5.2 \pm 0.2$ & $4.5 \pm 0.2$ & $3.7 \pm 0.2$ \\
$(6)$ & $5.7 \pm 0.3$ & $5.0 \pm 0.4$ & $4.1 \pm 0.2$ & $3.6 \pm 0.2$ \\
(7) & $4.7 \pm 0.2$ & $4.0 \pm 0.2$ & $3.6 \pm 0.3$ & $3.2 \pm 0.2$ \\
\hline
\end{tabular}

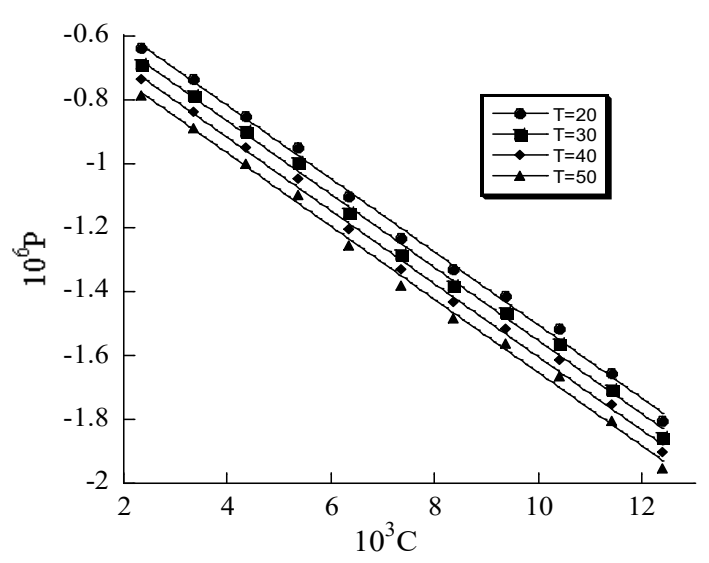

Figure 2. Typical plots of $P$ against $C$ for (2) with benzylamine at various temperatures ( $T=293$ to $323 K$ ) in DMSO, $I=0.1 \mathrm{M}$. $P=\left(C_{A}^{0} C_{D}^{0}\right) /\left(A-A_{A}^{0}-A_{D}^{0}\right)$ and $C=\left(C_{A}^{0}+C_{D}^{0}\right)$.

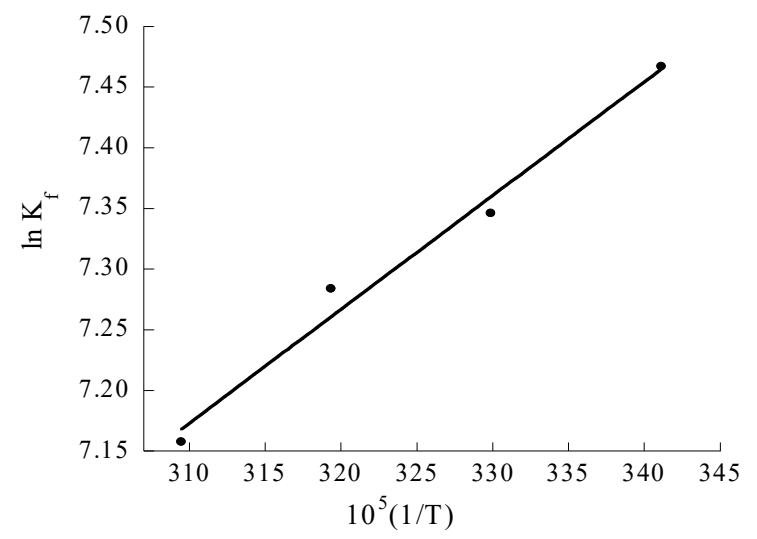

Figure 3. The plot of $\ln K_{f}$ against $1 / T$ for (2) titrated with 
with an increasing in electron-withdrawing of the equatorial ligands, the formation constants decrease (Table 5).

According to the electronic effect of the substituents, the Schiff base complex with the electron withdrawing group must have highest $K_{\mathrm{f}}$ values compared with the electron donating group. But the result obtained in this work contradicts that.

It seems that in the five-coordinated complexes, water or a solvent molecule occupies the sixth position [Eq. (5)], this would decrease the tendency of the complexes toward the interaction with the donors ${ }^{[36]}$ [Eq. (1)].

$$
\left[\mathrm{Co}(\text { Chel })\left(\mathrm{PBu}_{3}\right)\right]^{+}+\mathrm{S} \rightleftharpoons\left[\mathrm{Co}(\mathrm{Chel})\left(\mathrm{PBu}_{3}\right) \mathrm{S}\right]^{+}
$$

where $\mathrm{S}=\mathrm{H}_{2} \mathrm{O}$ or solvent molecule.

Concerning the stabilization of the five-coordinate complex, the donation power of the Schiff base is important. Therefore, the cobalt atom in (6) complex has more acceptor property than the other type of the complexes and forms more stable complex with $\mathrm{H}_{2} \mathrm{O}$ or solvent molecule [Eq. (5)]. Therefore, its tendency for the reaction with donors decreases, hence its formation constant, $K_{\mathrm{f}}$, is lower.

\section{THE EFFECT OF THE SUBSTITUENT POSITIONS ON FORMATION CONSTANT}

To study the effect of the position of substituents on the interaction of the cobalt(III) complexes, 3-OMe, 4-OMe substituents on the equatorial Schiff base of the complexes were selected. The results show the following trend in the adduct formation between cobalt(III) Schiff bases and benzylamine as donor:

$$
\text { 3-OMe > 4-OMe. }
$$

The presence of methoxy group in ortho position with respect to the phenolic oxygen in (1) decreases the acceptor property of the complex compared with complex (2) in which the methoxy group is in the meta position with respect the phenolic oxygen. Therefore, the expecting trend is as following:

4-OMe > 3-OMe.

But the results in this work show the reverse, this was attributed to the solvent effect (Table 5).

\section{The Effect of the Axial Ligands}

The axial phosphine ligands, due to their steric and electronic influence, affect the trend of the five coordinated complexes toward the donor ligands. It seems that the steric effect of the axial ligands is more important than the equatorial ligands. ${ }^{[37,38]}$ The formation constants for (5) and (7) with benzylamine in DMSO solvent increased according to the following trend (Table 5):

$$
\mathrm{PBu}_{3}>\mathrm{PMePh}_{2} \text {. }
$$

The phosphine ligands have an important steric factor that it can decrease the trend of the five-coordinated complex toward the donor bases. This factor is shown by Tolman's cone angle. The cone angle for $\mathrm{PPh}_{2} \mathrm{Me}$ and $\mathrm{PBu}_{3}$ are $136^{\circ}$ and $132^{\circ}$, respectively. ${ }^{[39,40]}$ The steric effect increases with increasing in the cone angle. So by increasing the cone angle in $\mathrm{PPh}_{2} \mathrm{Me}$, the formation constant is decreased.

The electronic effects of the phosphines have been expressed by $\sigma^{*}$ values of Taft (Taft constants). $\sigma^{*}$ values for $\mathrm{PBu}_{3}$ and $\mathrm{PPh}_{2} \mathrm{Me}$ are -0.390 and +1.18 , respectively. ${ }^{[41-43]}$ Also, the phenyl withdrawing groups decrease the basic properties of $\mathrm{PPh}_{2} \mathrm{Me}$ with respect to $\mathrm{PBu}_{3}$. The formation constants increase according to the following trend:

$$
\mathrm{PBu}_{3}>\mathrm{PMePh}_{2} \text {. }
$$

It seems that the formation constants are affected by the steric and electronic effects of phosphines as axial ligand.

\section{The Effect of Donors}

In this work, we have examined some primary, secondary and tertiary amines such as, $n$-butyl-, sec-butyl-, tert-butyl-, benzylamine, diethylamine, di(n-butyl)amine and tri( $n$ butyl)amine to measure the relative binding constants for a range of sterically and electronically varied amines.

The trend of the formation constants to amines is as following:

benzylamine $>n$-butylamine $>$ sec-butylamine $>$

$$
\text { tert-butylamine }
$$

The electronic effect contribution of amines is shown by $\sigma^{*}$ values of Taft, which are $+0.85,+0.77,+0.68$, and +1.20 for $n$-butylamine, sec-butylamine, tert-butylamine, and benzylamine, respectively. ${ }^{[4]}$ In addition to the electronic property, amines have an important steric factor that is shown by Trogler's cone angle. ${ }^{[45]}$ The cone angles for benzylamine, sec-butylamine and tert-butylamine are $106^{\circ}$, $113^{\circ}$ and $123^{\circ}$, respectively. The cone angle for $n$-butylamine is unpublished. The steric interaction is increased with increasing in cone angle. The formation constants were increased by decreasing the cone angle (Table 6). Diethylamine, di(n-butyl)amine and tri( $n$-butyl)amine showed very weak interaction with the complexes. Therefore, the results show that the steric factor is more important.

Table 6. The formation constants, $10^{-2} K_{\mathrm{f}}\left(\mathrm{L} \mathrm{mol}^{-1}\right)$, for the interaction of (5) with various amines in DMSO solvent.

\begin{tabular}{ccccc}
\hline Amines & 293 & 303 & 313 & 323 \\
\hline benzylamine & $6.4 \pm 0.3$ & $5.2 \pm 0.5$ & $4.5 \pm 0.2$ & $3.7 \pm 0.2$ \\
$n$-butylamine & $5.4 \pm 0.2$ & $4.7 \pm 0.1$ & $3.9 \pm 0.2$ & $3.5 \pm 0.4$ \\
sec-butylamine & $4.6 \pm 0.1$ & $3.9 \pm 0.2$ & $3.3 \pm 0.1$ & $3.0 \pm 0.1$ \\
ter-butylamine & $2.3 \pm 0.1$ & $2.0 \pm 0.1$ & $1.9 \pm 0.1$ & $1.7 \pm 0.1$ \\
\hline
\end{tabular}




\section{Thermodynamic Calculations}

To have a better understanding of the thermodynamics of the complexation reaction, the enthalpic and entropic contributions of the reaction were evaluated. The values of the corresponding standard thermodynamic quantities are given in Table 7. It is immediately obvious from these data, that in all of cases, the negative signs of $\Delta G^{\circ}$ is meant to indicate spontaneous interaction processes. Also, the standard enthalpy values are negative with positive entropic changes. This means that the complexation processes between the cobalt(III) complexes and the amines are both enthalpy and entropy stabilized.

The $\Delta H^{\circ}$ value and its sign, is dependent on two factors: one of these factors, is the solvation effect, the other one is the heat of formation of the complex. ${ }^{[46]}$ In these studies, the heat of formation is negative because of bond formation in all reactions. The solvation effect for five and six-coordinate complexes is not different due to the same charge, although it seems likely that the fivecoordinate complex is better solvated because it is smaller and more polar than the six-coordinate complex. The solvation effect for the donors is related to the interaction of solvent with the amines and this contribution to $\Delta H^{\circ}$ may be positive once equilibrium is reached.

In all cases, we found that the $\Delta H^{\circ}$ values are negative. Therefore, this shows that the complex-formation contribution of $\Delta H^{\circ}$ values is more important (Table 7). The enthalpy changes of amines toward these complexes (according to the substituents, phosphine axial ligands and different amines) are related to the equilibrium constants for these systems and with enhancing the tendency of complex formation, the enthalpy changes become more negative.

The $\Delta S^{\circ}$ value and its sign are also dependent on two factors: one of these factors is the difference in the number of the particles of the initial substances and the product complexes. The $n$ for all the systems studied is -1 .
Concerning the first factor, the entropy change is decreased. The second factor is the liberation of the solvent molecules from the solvation shells. ${ }^{[46]}$ Among the factors, which affect $\Delta S^{\circ}$ is the solvation of the amines. The positive $\Delta S^{\circ}$ values may be explained by dehydration occurring during the interactions of solute molecules.

According to the electronic factor of the amines, as the solvent molecules released during the adduct formation is higher, the $\Delta S^{\circ}$ becomes more positive ( Table 7). With reference to the second factor, the entropy change is increased. The net entropy changes for all reactions are positive, so it shows that the second factor is more important. In most of cases, the entropy changes of the amines toward the complexes are almost related to the equilibrium constants for these systems and with increasing complex formation, the entropy changes are more positive (Table 7).

\section{CONCLUSIONS}

The synthesis and characterization of some new five coordinated symmetrical and unsymmetrical cobalt(III) complexes derived from 3,4-diaminobenzophenone were performed. The formation constants, $K_{\mathrm{f}}$, and the thermodynamic parameters for the above adducts of the complexes with aliphatic amines as donor were determined spectrophotometrically and the results are as follow:

1. The formation constants changed according to the following trend due to the steric and the electronic factors of the cobalt(III) complexes: $\mathrm{N}^{\prime}-5-\mathrm{OMe}>\mathrm{N}^{\prime}-5-\mathrm{H}>\mathrm{N}^{\prime}-5-\mathrm{Br}>\mathrm{N}^{\prime}-5-\mathrm{Cl}$.

2. The trend of the formation constants of cobalt(III) Schiff base complexes toward the position of methoxy group on the equatorial Schiff base is following:

$\mathrm{N}, \mathrm{N}^{\prime}-3-\mathrm{OMe}>\mathrm{N}, \mathrm{N}^{\prime}-4-\mathrm{OMe}$.

Table 7. The thermodynamic parameters, $\Delta H^{\circ}, \Delta S^{\circ}$ and $\Delta G^{\circ}$ for all the systems in DMSO solvent

\begin{tabular}{|c|c|c|c|c|}
\hline Compounds & Amines & $-\Delta H^{\circ} / \mathrm{kJ} \mathrm{mol}^{-1}$ & $\Delta S^{\circ} / \mathrm{J} \mathrm{K}^{-1} \mathrm{~mol}^{-1}$ & $-\Delta G^{\circ} / \mathrm{kJ} \mathrm{mol}^{-1(\mathrm{a}}$ \\
\hline (1) & Benzylamine & $16.43 \pm 3.03$ & $11.04 \pm 3.87$ & $19.72 \pm 1.12$ \\
\hline$(2)$ & Benzylamine & $7.79 \pm 0.72$ & $35.48 \pm 2.34$ & $18.36 \pm 0.78$ \\
\hline (3) & Benzylamine & $14.56 \pm 0.15$ & $5.33 \pm 0.53$ & $16.16 \pm 0.22$ \\
\hline (4) & Benzylamine & $15.57 \pm 0.66$ & $6.04 \pm 0.85$ & $17.35 \pm 0.93$ \\
\hline (5) & Benzylamine & $14.08 \pm 0.65$ & $5.65 \pm 0.56$ & $15.75 \pm 0.84$ \\
\hline (6) & Benzylamine & $12.41 \pm 0.70$ & $10.48 \pm 2.52$ & $15.66 \pm 1.05$ \\
\hline (5) & $n$-butylamine & $11.70 \pm 0.67$ & $12.35 \pm 2.20$ & $15.50 \pm 0.94$ \\
\hline (5) & sec-butylamine & $11.44 \pm 0.70$ & $11.87 \pm 2.36$ & $15.02 \pm 0.98$ \\
\hline (5) & tert-butylamine & $7.56 \pm 0.79$ & $19.34 \pm 2.65$ & $13.35 \pm 0.98$ \\
\hline (7) & Benzylamine & $9.93 \pm 0.46$ & $17.02 \pm 1.57$ & $15.00 \pm 0.65$ \\
\hline
\end{tabular}

(a) $\Delta G^{\circ}$ values are calculated from $\Delta G^{\circ}=-R T \ln K_{\mathrm{f}}$ at $T=303 \mathrm{~K}$. 
3. The following binding trend of the donors toward a given cobalt(III) Schiff base complex is: benzylamine $>n$-butylamine $>$ sec-butylamine $>$ tert-butylamine

4. The trend of the formation constants of the cobalt(III) Schiff base complexes toward a given donor according to the phosphine axial ligands is as following:

$$
\mathrm{PBu}_{3}>\mathrm{PPh}_{2} \mathrm{Me}
$$

Acknowledgment. We are grateful to Shiraz University Research Council and Persian Gulf University Research Council for their financial support.

\section{REFERENCES}

[1] D. S. Leela, B. Ushaiah, G. Anupama, M. Sunitha, C. G. Kumari, J. Fluorescence 2015, 25, 185.

[2] H. Zafar, A. Kareem, A. Sherwani, O. Mohammad, M. A. Ansari, H. M. Khan, J. Photochem. Photobiol. B 2015, 142, 8.

[3] A. B. Begum, N. D. Rekha, B. C. V. Kumar, V. L. Ranganatha, S. A. Khanum, Bioorg. Med. Chem. Lett. 2014, 24, 3559.

[4] P. K. Mascharak, Coord. Chem. Rev. 2002, 225, 201.

[5] H. Temel, S. Pasa, Y. S. Ocak, I. Yilmaz, S. Demir, I. Ozdemir, Synth. Metal. 2012, 161, 2765.

[6] S. Jyothi, G. R. Rao, K. Shashank, K. Sridhar, A. Reddy, P. Someshwar, S. J. Swamy, Indian J. Chem. A 2014, 53, 535.

[7] V. Mirkhani, M. Moghadam, Sh. Tangestaninejad, I. Mohammadpoor-Baltork N. Rasouli, Catal. Commun. 2008, 219.

[8] E. L. Chang, C. Simmers, D. A. Knight, 2010, 3, 1711.

[9] A. Bottcher, T. Takeuchi, M. I. Simon, T. J. Meade, H. B. Gray, J. Inorg. Biochem. 1995, 59, 221.

[10] T. Takeuchi, A. Böttcher, C. M. Quezada, T. J. Meade, H. B. Gray, Bioorg. Med. Chem. 1999, 7, 815.

[11] G. B. Bagihalli, P. G. Avaji, S. A. Patil, P. S. Badami, Eur. J. Med. Chem. 2008, 43, 2639.

[12] A. C. Rizzi, C. D. Brondino, R. Calvo, R. Baggio, M. T. Garland, R. E. Rapp, Inorg. Chem. 2003, 42, 4409.

[13] G. Li, F. F. Zhang, H. Chen, H. F. Yin, H. L. Chen, S. Y. Zhang, J. Chem. Soc. Dalton Trans. 2002, 2, 105.

[14] M. Amirnasr, K. J. Shenk, A. Gorji, R. Vafazadeh, Polyhedron 2001, 20, 695.

[15] E. A. Moore, Int. J. Mol. Sci. 2003, 3, 873.

[16] A. Bottcher, T. Takeuchi, K. I. Hardcastle, T. J. Meada. H. B. Gray, D. Cwikel, M. Kapon, Z. Dori, Inorg. Chem. 1997, 36, 2498.

[17] A. M. Abu-Dief, I. M. A. Mohamed, Beni-Suef Univ. J. Basic Appl. Sci. 2015, 4, 119.

[18] M. Asadi, S. Torabi, Kh. Mohammadi, Monatsh.
Chem. 2013, 144, 1635.

[19] Kh. Mohammadi, M. Niad, A. Irandoost, Spectrochim. Acta A 2013, 107, 145.

[20] Kh. Mohammadi, M. Niad, T. Jahfari, Spectrochim. Acta A 2014, 122, 179.

[21] M. Asadi, S. Torabi, Kh. Mohammadi, Spectrochim. Acta A 2014, 122, 676.

[22] M. Asadi, H. Sepehrpour, Kh. Mohammadi, J. Serb. Chem. Soc. 2011, 76, 63.

[23] M. Asadi, M. Setoodeh Khah, J. Iran. Chem. Soc. 2010, 7, 875.

[24] M. Asadi, M. B. Ahmadi, Kh. Mohammadi, Z. Asadi, A. H. Sarvestani, J. Chem. Thermodyn. 2004, 36, 141.

[25] M. Asadi, Z. Asadi, S. Barzegar Sadi, L. Zarei, F. Moosavi Baigi, Z. Amirghofran, Spectrochim. Acta A. 2014, 122, 118.

[26] A. Ercag, M. Sahin, A. Koca, E. Bozkur, J. Coord. Chem. 2013, 66, 1635.

[27] A. B. P. Lever, Inorganic Electronic Spectroscopy, 2nd ed., Elsevier, New York, Amsterdam, 1984.

[28] M. Tumer. C. Celik. H. Koksal, S. Serin, Trans. Met. Chem. 1999, 24, 525.

[29] Y. L. Zhang, W. J. Ruan, X. J. Zhao, H. G. Wang, Z. A. Zhua, Polyhedron 2003, 22, 1535.

[30] E. Erdem, E. Y. Sari, R. Kilinçarslan, N. Kabay, Transition Met. Chem. 2009, 34, 167.

[31] P. P. Dholayika, M. N. Patel, Synth. React. Inorg. MetOrg. Nano-Chem. 2004, 34, 383.

[32] A. A. Khandar, S. A. Hosseini-Yazdi, Polyhedron 2003, 22, 1481.

[33] S. Madhupriya, K. P. Elango, Spectrochim. Acta, A: Mol. Biomol. Spect. 2012, 97, 100.

[34] P. Pattanayak, J. L. Pratihar, D. Patra, P. Brandao, V. Felix, Inorg. Chim. Acta 2014, 418, 171.

[35] J. A. A. Ketelaar, C. Van De Stolpe, A. Coulsmit, W. Dzcubes, Rec. Trav. Chim. 1952, 71, 1104.

[36] M. Asadi, A. H. Sarvestani, M. Abbasi, J. Chem. Res. 2007, 56.

[37] G. Costa, G. Tauger, G. Mestroni, A. Puxeddu, R. Costanzo, J. Chem. Soc. A 1971, 2504.

[38] C. W. Smith, G. W. Van Loon, M. C. Barid, Can. J. Chem. 1976, 54, 1875.

[39] C. A. Tolman, Chem. Rev. 1977, 77, 313.

[40] T. L. Brown K. J. Lee, Coord. Chem. Rev. 1993, 128, 89.

[41] R. W. Taft Jr, Steric Effects in Organic Chemistry (Ed. M. S. Newman), Wiley, New York, 1956.

[42] W. A. Henderson Jr, C. A. Streuli, J. Am. Chem. Soc. 1960, 82, 5791.

[43] C. Babij, A. J. Poe, J. Phys. Org. Chem. 2014, 17, 162.

[44] H. K. Hall Jr, J. Am. Chem. Soc. 1957, 79, 5441.

[45] A. L. Seligson, W. G. Trogler, J. Am. Chem. Soc. 1991, 113, 2520.

[46] S. Ahrland, Helv. Chim. Acta 1967, 50, 306. 